\title{
质谱在金属抗肿瘤化合物分子作用机理研究中的 应用
}

\author{
吴鬼, 罗群, 赵耀, 郑伟, 汪福意* \\ 北京分子科学国家实验室, 北京国家质谱中心, 活体分析化学中国科学院重点实验室, 中国科学院化学研究所, 北京 100190 \\ *通讯作者, E-mail: fuyi.wang@iccas.ac.cn

\begin{abstract}
摘要软电离质谱, 包括电喷雾质谱(ESI-MS)和基质辅助激光解吸电离质谱(MALDI-MS) 已成为研究金属 抗肿瘤药物与蛋白质、DNA等生物大分子相互作用最强有力的工具. 质谱成像技术在组织、细胞水平上探 索金属抗肿瘤化合物作用机理研究上的应用也方兴未艾. 本文基于在金属抗肿瘤配合物分子作用机理研究 中的工作进展, 系统地总结、评述质谱在铂基和钓基金属抗肿瘤配合物分子作用机理研究中的应用, 介绍质 谱研究金属抗肿瘤配合物与蛋白质和DNA相互作用及作用位点的最新研究成果, 并展望质谱在这一前沿交 叉领域的应用前景和趋势.
\end{abstract}

关键词质谱, 金属抗肿瘤药物, 铂, 钉, 分子作用机理

\section{1 引言}

顺铂对肿瘤细胞增殖抑制活性的偶然发现 ${ }^{[1,2]}$ 及 其在实体肿瘤临床治疗上的广泛应用 ${ }^{[3]}$, 标志着无机 药物化学学科的复兴和崛起. 但是, 作为一种细胞毒性 药物, 顺铂缺乏区分增殖较快的正常细胞和癌细胞的 能力, 由此产生严重的毒副作用如肾毒性、耳毒性、 恶心和呕吐等, 限制了它的临床应用. 另外, 顺铂所引 起的DNA损伤不仅导致恶性肿瘤细胞坏死, 还能在基 因水平上诱导一系列的抗调亡反应, 降低癌细胞对顺 铂治疗的敏感度. 细胞通过其主动排出机制、去毒性 化和DNA修复机制等减少药物在胞内的聚集, 从而产 生对药物的抵抗而降低治疗水平, 即产生获得性抗药 性 ${ }^{[4,5]}$. 因而, 研究者将目光转向其他金属化合物, 期望
发现克服顺铂及第 2 代、第 3 代铂类抗癌药物的缺陷, 而且疗效更好的金属抗肿瘤药物.

金属钉以其多样性、可控的配位化学性质, 与铂近 似的配体交换速率, 以及生理条件下多价态 $(+2 、+3$ 、 $+4)$ 稳定存在的特性获得越来越多的关注 ${ }^{[6-8]}$. 目前已 进入II期临床试验的两种钌基抗肿瘤化合物NAMI-A 和KP1019均为 3 价钓化合物 ${ }^{[9]}$. 其中KP1019对原发性 肿瘤具有显著的增殖抑制活性 ${ }^{[10]}$, 但DNA并不是其唯 一的靶标 ${ }^{[11]}$, NAMI-A则只对转移的肿瘤有效 ${ }^{[12]}$. 但是, 迄今为止, 3 价钉金属配合物抗癌作用的分子机理还不 清楚. Clarke等 ${ }^{[13,14]}$ 认为 $\mathrm{Ru}^{3+}$ 可能在体内被还原为 $\mathrm{Ru}^{2+}$ 而发挥作用. 基于此, 近年来2价钓抗肿瘤配合物的 设计和开发取得了较大进展. 其中, Sadler等 ${ }^{[15 \sim 17]}$ 报道 的一系列半三明治钢琴登(half-sandwich piano-stool)结

引用格式: 吴魁, 罗群, 赵耀, 郑伟, 汪福意. 质谱在金属抗肿瘤化合物分子作用机理研究中的应用. 中国科学: 化学, 2017, 47: 233-248

Wu K, Luo Q, Zhao Y, Zheng W, Wang F. Investigations of molecular mechanism of action of metal-based anticancer complexes by mass spectrometry. Sci Sin Chim, 2017, 47: 233-248, doi: 10.1360/N032016-00146 
构的有机金属钉化合物 (通式: [( $\eta^{6}$-arene) $\left.\mathrm{Ru}(\mathrm{YZ})(\mathrm{X})\right]$, 其中, arene为芳烃配体, $Y Z$ 为螯合配体, $X$ 为离去基 团)和Dyson等 ${ }^{[7,18-20]}$ 设计合成的一类含有机磷配体 的有机金属钓配合物 RAPTA ( $\left[\mathrm{RuCl}_{2}\left(\eta^{6}\right.\right.$-arene)(pta) $]$, $\mathrm{pta}=1,3,5$-triaza-7-phospha-adamantane), 具有引人瞩目 的抗肿瘤活性. 部分RAPTA系列配合物具有与NAMI-A 相似的活性, 即只对二级转移的肿瘤才有抑制效果 ${ }^{[21]}$. Sadler等 ${ }^{[15,22]}$ 开发的有机金属钓配合物能通过对芳烃 配体、螯合配体和离去基团进行结构上的修饰、改 造, 调节这类化合物的理化性质和抗肿瘤活性. 其中以 乙二胺(en)为鳌合配体, 氯为离去基团的系列化合物 $\left[\left(\eta^{6}\right.\right.$-arene $\left.) \mathrm{Ru}(\mathrm{en})(\mathrm{Cl})\right]\left[\mathrm{PF}_{6}\right]$ 在体内和体外研究中表现出 较好的抗癌活性, 并且随着芳香烃配体体积的增大, 其 活性呈现增长趋势. 例如, 对人卵巢癌细胞株A 2780 的 抑制活性随芳香烃配体体积增大的顺序为: 苯(ben)< 对甲基异丙基苯 (cym)<联苯(bip)<二氢葱 (dha) <四氢 葱(tha). 其中联苯配合物的活性与卡铂相当, 四氢葱 配合物的活性与顺铂近似, 而且与顺铂没有交叉抗药 性 ${ }^{[23]}$.

金属抗肿瘤药物大多通过静脉注射方式给药. 所 以, 尽管DNA被认为是以顺铂为代表的金属抗肿瘤药 物的终极靶标, 药物在进入血液系统后不可避免地将 会与血浆、血清中的蛋白质, 特别是高丰度蛋白质作 用. 进入细胞后, 胞内蛋白质也将与DNA竞争和金属 配合物的结合. 金属抗肿瘤药物与蛋白质的相互作用 是影响药物生物利用度的关键因素, 同时也是其产生 毒副作用和细胞抗药性的可能原因 ${ }^{[5,24]}$. 近年的研究 表明, 蛋白质也可能是金属抗肿瘤药物的药效靶标, 通过与金属药物-DNA靶向作用产生协同效应, 增加 药物的抗肿瘤活性 ${ }^{[25,26]}$. 因而, 金属抗肿瘤药物与蛋白 质的作用也是其药理学研究的重要组成部分.

金属抗肿瘤药物与DNA、蛋白质等生物大分子的 相互作用具有多样性和复杂性. 随着基于软电离技术 的电喷雾电离质谱(ESI-MS)、基质辅助激光解吸电离 质谱(MALDI-MS)等的日益成熟, 质谱分析以其灵敏 度高、所需样品量少、耗时短等优点, 已成为研究药 物分子与生物大分子相互作用强有力的工具 ${ }^{[27,28]}$. 通 过质谱分析, 不仅能够鉴定金属药物与蛋白质、DNA 等生物大分子的作用方式和作用位点, 还可以结合 稳定同位素标记技术获得药物和靶分子结合的定量 信息. 与各种不同性能、不同维度色谱分离、富集
技术的联用, 使质谱分析能够直接分析较复杂的生 物样品 ${ }^{[29-31]}$, 在为药物分子机理研究提供丰富的化学 和生物信息的同时, 也极大地促进了质谱技术自身 的发展及其在生命科学领域的应用. Keppler等 ${ }^{[28]}$ 、

Hartinger等 ${ }^{[27]}$ 、Timerbaev ${ }^{[32]}$ 对质谱在研究金属抗肿 瘤化合物分子作用机理方面的应用分别进行了全面 的总结和评述. 本文将结合本课题组近年来在金属抗 肿瘤化合物分子作用机理研究中的进展, 系统地总结 ESI-MS和电感耦合等离子体质谱(ICP-MS)在金属抗 肿瘤化合物与蛋白质和DNA相互作用研究中的发展 动态, 并展望和分析质谱技术在这一前沿交叉领域未 来的应用前景和趋势.

\section{2 质谱研究金属抗肿瘤化合物与DNA的相 互作用}

DNA被普遍认为是细胞毒性抗肿瘤药物的终极 靶标. 金属类抗肿瘤药物与DNA的作用方式按是否 形成配位键分为共价结合和非共价结合 ${ }^{[33,34]}$. 顺铂 是能与DNA发生共价结合的经典抗肿瘤药物 ${ }^{[33]}$. 早 期在研究顺铂与DNA的相互作用时多应用核磁共振 波谱(NMR)、光谱(包括紫外/可见分光光度法、圆 二色谱法、拉曼光谱法等)、色谱、X射线单晶衍 射法(XRD)或传统的分子生物学技术等 ${ }^{[35-40]}$, 它们 在结合位点鉴定、结合方式、构型研究等方面获 得了大量有价值的信息. Berners-Price、Hambley、 Lippard、Lippert、Reedijk、Sadler等在这一领域做出 了突出的贡献 $[24,33,35 \sim 37,41-44]$. 他们的研究表明, 顺铂选 择性地与 DNA大沟内相邻的两个鸟嘌呤 $(G)$ 、或腺 嘌呤 $(A)$ 和鸟嘌呤、或相隔一个碱基的两个鸟嘌呤 之间的7位 $\mathrm{N}$ 原子以配位键形成链内交联(intrastrand crosslink, 包括1,2-GpG、1,2-ApG和1,3-GpNpG)或链间 交联(interstrand crosslink)复合物 ${ }^{[33,43,45,46]}$. 其中1,2-GG 和 1,2-AG 链内交联产物各占 47\% 50\% 和 23\% 28\%; $1,3-\mathrm{GNG}$ 链内交联产物、链间交联产物和单配位铂化 产物分别占到铂化DNA产物的 $8 \%$ 10\%和 $2 \%$ 3\% ${ }^{[47]}$.

与顺铂类似, DNA也是细胞毒性有机金属钉抗 肿瘤化合物 $\left[\left(\eta^{6}\right.\right.$-arene) $\left.\mathrm{Ru}(\mathrm{en})(\mathrm{Cl})\right]\left[\mathrm{PF}_{6}\right]$ (图 1 所示为该 系列配合物的典型代表)的潜在靶标. X射线晶体 衍射和NMR研究表明, 在中性 $\mathrm{pH}$ 条件下, 这类有机 金属钓配合物对4种DNA碱基的反应活性顺序为: $\mathrm{G}(\mathrm{N} 7)>\mathrm{T}(\mathrm{N} 3)>\mathrm{C}(\mathrm{N} 3)>\mathrm{A}(\mathrm{N} 7) 、 \mathrm{~A}(\mathrm{~N} 1)^{[48,49]}$. 乙二胺配体 

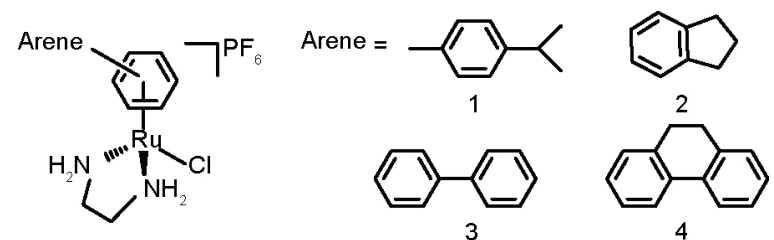

图 1 本文涉及的有机金属钉抗肿瘤配合物的化学结构式

的 $\mathrm{NH}_{2}$ 与鸟嘌呤上 6 位 $\mathrm{C}$ 上的 $\mathrm{O}$ 之间形成的氢键对于钉 化合物对 $\mathrm{G}$ 碱基的高选择性起关键性的作用 ${ }^{[48 \sim 50]}$. 芳 烃-嘌呤之间的憎水作用和 $\pi-\pi$ 堆积也增加钉与鸟嘌呤 N7结合的高选择性, 这一点在含多环芳烃配体的钌化 合物和DNA作用中更明显 ${ }^{[49,51 \sim 33]}$. 分子生物学和生物 物理研究证实了有机金属钉配合物与DNA作用时对 G碱基的高选择性 ${ }^{[54,55]}$.

随着质谱技术的快速发展, 特别是新型离子源 和高分辨质量分析器的开发和应用, 再加上与各种 不同类型的分离技术的结合, 质谱以其样品制备简 单、耗样量少、分辨率高、灵敏度高、检测范围 宽、分析速度快等优点在金属药物-DNA相互作用 研究方面的应用越来越广泛和深入 ${ }^{[27,56,57]}$. 与基于 质谱的蛋白质组学研究类似, 质谱研究金属药物与 DNA的相互作用也有“自下而上”(bottom-up)和“自 上而下”(top-down)两种方法. 自下而上的方法一般 借助于DNA外切酶(如蛇毒磷酸二酯酶(snake venom phosphodiesterase, SVP) 和牛脾磷酸二酯酶 (bovine spleen phosphodiesterase, BSP) 等), 将DNA-药物复合 物酶解成片段(图2(a)), 经由液相色谱分离后进行质 谱分析. DNA外切酶能够识别碱基之间的磷酸二酯 键, 从 $5^{\prime}$ 端(BSP)或 $3^{\prime}$ 端(SVP) 将DNA 链上的磷酸二酯 键逐个水解为核苷酸碎片. 当DNA碱基被药物修饰 时, 水解会停止在被修饰的碱基位点 ${ }^{[58]}$. 通过对药物 修饰的DNA片段的质谱分析, 就可以获得药物-DNA 相互作用位点的信息. 这种方法在鉴定铂类抗癌药 物与DNA的相互作用位点上发挥了重要的作用. 例 如, Ralph等 ${ }^{[59]}$ 利用ESI-MS 分析顺铂与不同序列的 8 碱 基和 16 碱基寡核苷酸链的复合物的 BSP、SVP酶解 产物, 成功鉴定出低丰度的1,2-GA交联产物. Chottard 等 ${ }^{[60]}$ 也同时利用 BSP和 SVP 两种 DNA外切酶, 结合 ESI-MS和MALDI-MS研究了 $\left[\mathrm{Pt}\left(\mathrm{NH}_{3}\right)_{3}\left(\mathrm{H}_{2} \mathrm{O}\right)\right]^{2+}$ 与单链 寡核苷酸d(TTGGCCAA) 的相互作用, 发现铂化合物 倾向于与 $5^{\prime}-\mathrm{G}$ 结合, 其反应速率是与 $3^{\prime}-\mathrm{G}$ 结合的两倍.
Bierbach等 ${ }^{[61]}$ 在应用液质联用(LC-MS) 技术研究顺铂 类似物 $[\mathrm{PtCl}(\mathrm{en})(\mathrm{ACRAMTU}-\mathrm{S})]\left(\mathrm{NO}_{3}\right)_{2}(\mathrm{ACRAMTU}=1-$ [2-(acridin-9-ylamino)ethyl]-1,3-dimethylthiourea) 与小 牛胸腺DNA (CT-DNA) 的酶解反应产物时, 发现铂配 合物中的大环DNA插入式配体改变了 2 价铂与 $\mathrm{G}$ 碱 基原本具有的高亲和性, 转而倾向于与 $\mathrm{A}$ 碱基配位, 这为设计新型靶向性铂配合物提供了重要的理论依 据. Sadler等 ${ }^{[62]}$ 在研究有机金属钉抗肿瘤配合物的早 期即应用ESI-MS研究了钌配合物 1 (图1)与寡核苷酸 d(ATACATGGTACATA)的反应, 利用SVP酶解钉化产 物, LC-MS分析表明, 钉的结合位点是鸟嘌呤碱基 $G$. 本课题组 ${ }^{[63]}$ 结合 SVP 外切酶酶解和 LC-ESI-MS 分析 进一步证实了有机金属钉抗肿瘤化合物 $2 、 3$ 对寡核 苷序列中 $\mathrm{G}$ 碱基的高选择性结合. 在该序列的类似序 列 $-\mathrm{C}_{7} \mathrm{G}_{8} \mathrm{~A}_{9}-、-\mathrm{A}_{7} \mathrm{G}_{8} \mathrm{~T}_{9}-、-\mathrm{T}_{7} \mathrm{G}_{8} \mathrm{~A}_{9}-$ 上, 我们还观察到 有机金属钉配合物与 $\mathrm{G}_{8}$ 碱基结合的反应速率和亲和 常数都受相邻碱基性质的影响, 表明钓配合物与DNA 的结合存在一定序列选择性. 进一步的LC-ESI-MS研 究还发现, 有机金属钉配合物能在双链DNA上的 G碱 基间发生迁移, 即从初始结合的 $\mathrm{G}$ 碱基上解离而游离 到互补链表面, 与互补链上相近的鸟嘌呤再结合 ${ }^{[64]}$. 其原因可能是由于DNA双螺旋产生较大的应力作用 造成的. 在生理条件下, 与DNA形成交联复合物的顺 铂很少发生链内或链间迁移 ${ }^{[65]}$, 除非在特别苛刻的色 谱分离条件, 如使用含高浓度氯化钠的流动相 ${ }^{[66]}$, 或 顺铂类似物中含有较大配体的情况下 ${ }^{[67 \sim 70]}$ 才可能发 生. 反铂配合物和三核铂配合物BBR3464在DNA链 上也有类似的链接异构化(linkage isomerization)现象 的报道 ${ }^{[71]}$.

前面已经提到芳烃配体的大小对有机金属钓配 合物抗肿瘤活性有较大的影响 ${ }^{[23]}$, 在鉴定钉配合物与 DNA的结合位点时也观察到, 较大的芳烃配体也可能 会影响DNA外切酶的效率, 干扰结合位点的鉴定 ${ }^{[72]}$. 在 利用 $5^{\prime}$ 核酸外切酶BSP水解钉配合物 $\mathbf{3}$ (图2(a)) 和单链 寡核苷酸 $5^{\prime}-\mathrm{CCCA}_{4} \mathrm{G}_{5} \mathrm{C}_{6} \mathrm{CC}-3^{\prime} 、 5^{\prime}-\mathrm{CCC}_{3} \mathrm{G}_{4} \mathrm{~A}_{5} \mathrm{CCC}-3^{\prime}$ 的 复合物时, $\mathrm{MS}$ 结果表明酶解位点停留在 $\mathrm{A}_{4}$ 上或 $\mathrm{C}_{3}$ 上, 与此前观察到的钓配合物对 $\mathrm{G}$ 碱基的高选择性相互矛 盾. 所以, 应用自上而下的质谱方法进一步研究了以 上两种钉化产物的钉化位点, 结果表明钉配合物单元 确实是结合在其中的 $\mathrm{G}$ 碱基上. 这一结果表明, 金属钌 中心结合的大体积配体, 如联苯等可能通过与相邻碱 
(a)

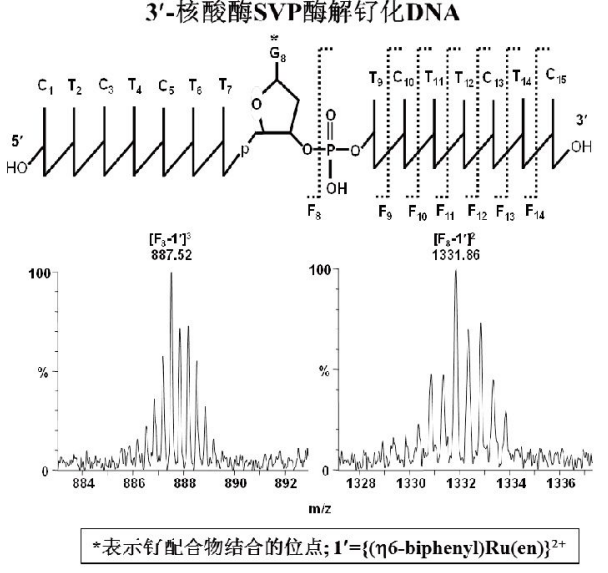

(b)

钓化DNA的CID碎裂

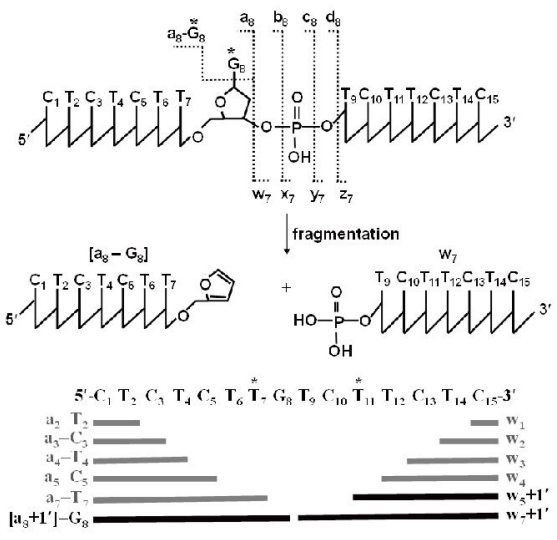

图 2 (a) 自下而上和(b)自上而下的质谱分析鉴定有机金属钓化合物与DNA结合位点示意图

基的 $\pi-\pi$ 堆积作用阻止了核酸外切酶碱基之间磷酸二 酯键的催化水解作用. 因此, 在利用核酸外切酶酶解 DNA-金属药物复合物鉴定药物的结合位点时, 应注 意配合物上大体积配体对酶解反应的影响 ${ }^{[72]}$.

除了应用DNA外切酶与LC-MS结合鉴定金属配 合物与DNA的作用位点之外, 还可以将多种不同性质 的DNA酶联合起来, 获得金属与DNA结合的更多信 息. 例如, Linscheid 等 ${ }^{\left[{ }^{73]}\right]}$ 将核酸酶benzonase、碱性磷 酸酶和核酸酶 $\mathrm{S} 1$ 联合使用, 应用 MS 定量分析了奥沙 利铂与DNA上鸟嘌呤和腺嘌呤碱基的相对结合量, 发 现两种产物之间的比例会随着反应时间的变化而变 化. 研究者还把这种联合酶解的方法应用在研究G-四 链体DNA与铂类配合物的作用位点鉴定上, 发现铂类 化合物仍可以与 G-四链体DNA形成G-G、G-A交联产 物. 但是, 相对于单链DNA, 铂对loop环上A碱基的亲 和力明显增强 ${ }^{[74,75]}$.

随着质谱仪器质量、分辨率的提高和母离子解离 技术的发展, 自上而下的质谱方法在鉴定药物与DNA 结合位点领域的应用也逐渐增加. 自上而下质谱分析 选择金属化合物与DNA复合物的准分子离子为母离子, 利用碰撞诱导解离(collision induced dissociation, CID) 或电子捕获解离 (electron capture dissociation, ECD)等 裂解技术, 将母离子裂解, 分析获得DNA碎片离子质 谱信息, 从而鉴定金属化合物与DNA的结合位点. 该 方法不需要经过酶解等前处理步骤, 因此能更好地保 留金属化合物和DNA相互作用的信息. DNA复合物母 离子在气相中的裂解具有一定规律, 一般情况下DNA
会先发生碱基丢失, 接下来是 $3^{\prime}$ 端 $\mathrm{C}-\mathrm{O}$ 键的断裂, 产生 $\mathrm{W}_{m-n}{ }^{-}$和 $\left[\mathrm{a}_{n}-\mathrm{B}_{n}\right]^{-}$互补离子 ( $m$ 为DNA链所含的碱基数, $n$ 为 $\mathrm{C}-\mathrm{O}$ 键断裂位置) (图 $2(\mathrm{~b}))^{[76,77]}$. 金属药物等小分子与 DNA共价结合不会对DNA的断裂产生很大影响, 因此 大大简化了质谱数据的解析, 在金属抗癌药物与DNA 相互作用研究中得到越来越多的青睐 ${ }^{[78-80]}$. Egger等 ${ }^{[79]}$ 利用傅里叶变换离子回旋共振质谱(FTICR-MS)研究 了顺铂与双链DNA的反应, 发现顺铂先以 $\left[\mathrm{Pt}\left(\mathrm{NH}_{3}\right)_{2} \mathrm{Cl}\right]^{+}$ 的形式与DNA形成单配位复合物, 然后再生成 1,2-或 1,3 -链间交联产物. Stucki等 ${ }^{[80]}$ 应用自上而下的质谱方 法研究顺铂与单分子、双分子和四分子 G四链体DNA 的反应时发现, 碎裂中双分子和四分子 $\mathrm{G}$ 四链体 DNA 会优先解链, 顺铂倾向于与G-四链体DNA链末端的碱 基结合. 前述在应用自下而上的质谱方法鉴定有机金 属钓配合物与单链DNA的结合位点, 受钓配合物中大 体积芳烃配体的影响, 鉴定结果与NMR等获得的结果 相矛盾. 所以, 采用CID方式直接碎裂单钓化的单链寡 核苷酸, 通过质谱分析获得的互补和阶梯式的钓化/非 钉化寡核苷酸碎片离子, 明确地鉴定出钉化合物在单 链DNA上的结合位点 ${ }^{[72]}$.

金属配合物与DNA的相互作用大多是动力学控 制的反应 ${ }^{[81]}$, 热力学稳定的最终产物往往出现在最 初发生配位反应的碱基位点上, 其结合强度和产率 都会受到DNA序列的影响, 而不同复合物的形成将 会导致不同的生物学效应 ${ }^{[36]}$. 因此, 金属化合物与 DNA相互作用的动力学研究对于研究金属抗癌药物 的作用机理具有重要意义. 基于此, 应用LC-ESI-MS 
研究了有机金属钉配合物 3 与 15 个碱基的单链DNA $5^{\prime}$-CTCTCTT ${ }_{7} \mathrm{G}_{8} \mathrm{~T}_{9}$ CTTCTC-3'的反应动力学, 发现在反 应初期, 除了与 $\mathrm{G}$ 碱基结合的单钓化产物外, 还有一个 新的单钓化DNA产物出现, 随着反应时间增加, 这一新 产物几乎消失. 该化合物与类似DNA序列 $\left(-\mathrm{C}_{7} \mathrm{G}_{8} \mathrm{~A}_{9}-\right.$ 、 $\left.-\mathrm{A}_{7} \mathrm{G}_{8} \mathrm{~T}_{9}-、-\mathrm{T}_{7} \mathrm{G}_{8} \mathrm{~A}_{9}-\right)$ 反应时也有类似现象. 但是, 当 使用DNA外切酶酶解钉化产物后, 质谱分析只观察到 钉化合物与 $\mathrm{G}$ 碱基结合的产物. 可能的原因是该复合 物在热力学上不稳定, 在酶解过程中发生解离而被破 坏. 于是, 引入自上而下的质谱分析对该动力学优先 的钓化产物进行鉴定. 结合 CID解离方法, 通过对反 应30 min的产物进行自上而下质谱分析, 比较获得的 $\mathrm{w}$ 和a-B碎片, 鉴定出 $-\mathrm{T}_{7} \mathrm{G}_{8} \mathrm{~T}_{9}-$ 链上的 $\mathrm{T}_{7}$ 和 $\mathrm{T}_{11}$ 碱基都有 可能与钉结合, 形成单钉化的DNA复合物. 类似地, 我 们鉴定出钓配合物也能与其他 3 条类似序列中部的 $\mathrm{T}$ $\left(T_{6} 、 T_{7}\right.$ 或 $\left.T_{11}\right)$ 结合 ${ }^{[77]}$. 进一步的研究表明, 单链DNA 上的 $\mathrm{T}$ 碱基在动力学上能与 $\mathrm{G}$ 碱基竞争与钓的配位 ${ }^{[63]}$. 这是首次关于有机金属钓抗肿瘤配合物与DNA的 T碱 基结合的报道. 这个新位点的鉴定使我们相信 $\mathrm{T}$ 碱基 在有机金属钓抗肿瘤化合物的作用过程中可能扮演 重要的角色. 基于此, 本课题组应用自下而上和自上 而下相结合的质谱分析方法, 研究了人端粒DNA片段 $\mathrm{d}\left(\mathrm{A}_{1}\right.$ GGGTTAGGGTTAGGGTTAGGG $\left._{22}\right)$ 与有机金属钉 配合物的相互作用. 人端粒DNA片段是一段富 $\mathrm{G}$ 和 $\mathrm{T}$ 序列, 形成G-四链体结构后 G碱基间形成Hoogsteen氢 键占据钓化合物的结合位点 G-N7, 而T碱基则位于相 对灵活的外侧环上 ${ }^{[82,83]}$, 这种结构变化可能会改变 $\mathrm{G}$ 、 $\mathrm{T}$ 与钉的反应活性. 根据质谱分析证实, 有机金属钓基 团的主要结合位点确实是 $\mathrm{G}$-四链体末端外环上的 $\mathrm{T}$ 碱 基 $\mathrm{T}_{18}$ (或 $\left.\mathrm{T}_{17}\right)^{[63]}$. 随着反应时间的延长, $\mathrm{G}$ 结合的DNA 产物质谱峰相对强度没有明显变化, 而 $\mathrm{T}$ 结合的DNA 产物质谱峰相对强度则随着反应时间的延长而增加, 表明 $\mathrm{G}$-四链体外环上的 $\mathrm{T}$ 碱基在动力学和热力学上都 能与 $\mathrm{G}$-四分体平面上的 $\mathrm{G}$ 竞争和钓的结合. 进一步的 分子模拟结果显示, 钓配合物中乙二胺基团与相邻碱 基上的氢键作用，以及芳烃配体与碱基之间的 $\pi-\pi$ 电子 堆积作用提高了钉对 $\mathrm{T}$ 碱基的亲和力, 并有助于 $\mathrm{G}$-四 链体-小分子复合物结构的稳定性 ${ }^{[63]}$. 这一结果表明, 人类基因组中普遍存在的 G-四链体DNA有可能是细 胞毒性有机金属钉抗癌化合物的潜在作用靶标. 研究 也表明, 在金属药物的研究过程中, 对动力学过程的
探讨与对热力学稳定产物的研究同等重要, 因为药物 与动力学竞争力强的靶标的结合同样会对生命体信 号转导过程产生重要影响.

关于有机金属钉化合物与DNA相互作用的二级 质谱研究报道相对较少 ${ }^{[84]}$, 我们在一开始就选择了 5'-TpG和 5'-GpT两种二核苷酸作为模型分子, 探索钉 化DNA的CID解离模式, 获得了大量有助于结合位点 鉴定的信息. 在CID解离中, 有机金属钓配合物中的乙 二胺和芳烃配体会发生丢失, 甚至整个钓配位基团会 从钉化核苷酸上解离, 钉化合物与 $3^{\prime}$ 或 $5^{\prime}$ 端碱基结合 时会导致不同的碎裂方式, 最重要的, 发现 $\mathrm{G}$ 碱基相对 于 $\mathrm{T}$ 碱基极易从糖环上解离 ${ }^{[77]}$. 如果钓结合在 $\mathrm{G}$ 碱基 上, 这种解离将导致 $\mathrm{G}$ 结合位点信息的丢失. 所以, 自 上而下的质谱分析可能不太适合鉴定DNA上G碱基钌 化位点. 钓配合物的结合对DNA的CID特征碎裂没有 明显影响, 与DNA和顺铂 ${ }^{[9]}$ 、RAPTA配合物 ${ }^{[84]}$ 复合物 的CID碎裂相似, 主要产生互补的w和a-B碎片离子. 钓 与芳烃配体的作用一般较强, 化学键不易断裂. 但是 在RAPTA配合物中, 含磷配体强烈的反式效应(trans effect) 会使钓-芳烃键变弱, 在CID中发生解离 ${ }^{[29]}$. 钓和 乙二胺形成的 $\mathrm{Ru}-\mathrm{N}$ 键与铂和氨基配体的 $\mathrm{Pt}-\mathrm{N}$ 键类似, 在钉化、铂化DNA的二级质谱分析中都有可能发生 解离 ${ }^{[00,85,86]}$, 解析DNA复合物的二级质谱时需要特别 注意.

综上所述, 研究表明, 自下而上和自上而下两种质 谱分析方法在鉴定金属配合物与DNA的结合位点时 各有优势和不足(表1), 如果能将两者结合起来, 利用 两者的互补性, 将会对研究金属抗肿瘤化合物与DNA 的相互作用大有禆益.

\section{3 质谱鉴定金属抗肿瘤化合物与蛋白质的 结合位点}

绝大多数细胞毒性的金属抗肿瘤药物, 如临床上 使用最为广泛的顺铂及第2、3代铂类药物卡铂、奥沙 利铂等, 都是通过静脉注射方式给药. 从化学角度分析, 软Lewis酸性质的铂族金属, 如铂、钓等易和多肽、 蛋白质中含Lewis软碱基团的半胱氨酸、蛋硫氨酸、 组氨酸残基结合 (亲和力 $\mathrm{Cys}(-\mathrm{S})>\operatorname{Met}(-\mathrm{S})>-\mathrm{N}>-\mathrm{O}$ ), 生 成稳定的配合物 ${ }^{[87-92]}$. 因而, 静脉注射的金属抗肿瘤 药物在到达细胞内的药物靶标(DNA)之前, 胞内外蛋 白质中一些暴露于溶剂的半胱氨酸(Cys)、甲硫氨酸 
分析流程

(1) 获取完整的金属-靶分子药物复 合物质谱信息; (2) 选择合适的金 属-靶分子离子为母离子, 以CID、

自上而下 $\mathrm{ECD}$ 或IRMPD电离方法将复合物 top-down 裂解; (3) 获取含金属和不含金属 的碎片离子质谱信息, 鉴定药物 在靶分子上的结合位点
优点

样品不需要经过酶解等前处理步 骤, 能够最大限度地保留金属药物和 靶分子结合的结构信息, 并且可以 将金属药物与靶分子的结合位点确 定到单个氨基酸残基或碱基上
(1) 将金属-靶分子药物复合物酶解 成较小的片段; (2) 小片段混合物

自下而上 bottom-up 经液相色谱分离, 进行在线质谱分 析; (3) 结合肽段搜库和DNA碱基 比对技术鉴定金属化肽段或碱基片 段, 获取金属结合位点信息
能与多种不同色谱分离富集方法 联用, 序列覆盖率高, 可以获得 较多的金属结合位点信息, 适合 研究质量数较大的蛋白质或DNA 和金属药物的相互作用
缺点

蛋白质和DNA的裂解机理复杂, 大量 碎片离子的质谱解析非常困难, 一 般只适用于研究质量数较小的蛋白 质或DNA片段 $(<10 \mathrm{kD})$ 与金属药物 的相互作用; 在DNA-金属复合物的 二级质谱分析中, 碱基的优先丢失 可能会影响位点鉴定, 不太适合鉴 定DNA上的G碱基金属化位点

酶解不仅耗时而且会涉及使用高浓度 的变性剂、还原剂等,可能导致金属 -蛋白质配位键的解离使位点信息丢 失; 对于DNA-药物复合物, 含较大配 体的金属基团可能影响DNA外切酶 的效率, 进而影响金属结合位点鉴定
(Met)和组氨酸(His)等氨基酸会与它们配位形成稳定 的金属-蛋白质复合物. 例如, 血液中含量丰富的血 清白蛋白(HSA)、转铁蛋白(Tf), 细胞内的铜伴侣蛋白 (Atox1、Cox17等)、金属硫蛋白(MT)、谷胱甘肽转移 酶 $\pi(\mathrm{GST} \pi)$ 、蛋白酪氨酸磷酸酶 $1 \mathrm{~B}$ (PTP1B)等. 分子 水平的研究证实, 这些细胞内外的蛋白质都会参与或 影响了顺铂或有机金属钓抗肿瘤化合物的药理学过 程, 包括药物传输、代谢、细胞凋亡信号转导等, 也 可能涉及细胞抗药性和毒副作用的产生 ${ }^{[5,87,93]}$. 所以, 研究金属抗肿瘤药物和蛋白质的相互作用对更好地 理解药物作用机理, 优化药物分子结构非常重要.

应用质谱研究金属药物和蛋白质的相互作用同 样有自下而上和自上而下两种途径. 自下而上质谱是 最为常用的分析方法, 其一般流程如图3所示. 金属药 物和蛋白质反应的混合物通过超滤或透析的方法除 去没有结合的药物分子, 药物-蛋白复合物经由变性、 还原二硫键等处理后, 选择合适的蛋白酶(如胰蛋白 酶)酶解后, 应用LC-ESI-MS分析肽段混合物, 鉴定金 属结合的肽段, 结合蛋白质侧链化学修饰, 即可确定 金属药物在蛋白质上的结合位点 ${ }^{[94]}$. 鉴定金属配合物 在多肽上氨基酸残基结合位点的另一个方法是二级 质谱(串联质谱 MS/MS)方法. 在一级质谱鉴定出金属 修饰的肽段后, 选择该金属结合肽段的离子为母离子, 利用碰撞诱导解离 (CID)或电子捕获解离(ECD)等技 术裂解金属化肽段. 多肽(或蛋白质)的碎裂根据解离 方法不同在肽键不同位置断裂, 产生不同的互补离子

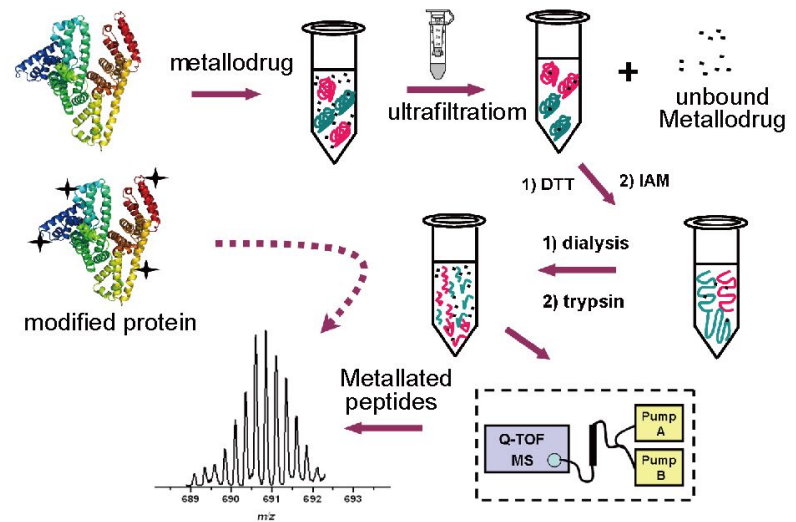

图 3 自下而上的质谱法分析研究金属药物与蛋白质相互 作用的一般流程示意图(网络版彩图)

(图4). CID裂解主要产生y, b离子对, 而ECD裂解则主 要产生 $\mathrm{c}, \mathrm{y}$ 互补离子. 根据质谱检测到的含金属离子 的碎片离子, 即可确定金属准确的结合位点 ${ }^{[95,96]}$.

血清白蛋白(albumin)是血清中丰度最高的蛋白质， 其与金属药物的相互作用, 对于药物的生物利用度、 毒副作用的产生起着至关重要的作用. 顺铂经静脉注 射给药后大部分 $\left(50 \%\right.$ 72\%)与血清白蛋白结合 ${ }^{[97]}, 3$ 价 钉类抗癌药物KP1019在给药后有 $80 \%$ 90\%与血清白 蛋白结合 ${ }^{[28]}$. Farrell等 ${ }^{[98]}$ 综合利用苂光光谱、NMR和 ESI-MS研究发现, 三核铂化合物BBR3464首先通过静 电和氢键等非共价作用与血清白蛋白结合, 然后可能 共价结合到蛋白表面的Cys34或Met298残基上,而这 有可能导致该药物不稳定并且失活. Sheldrick等 ${ }^{\left[{ }^{[1]}\right.}$ 利 


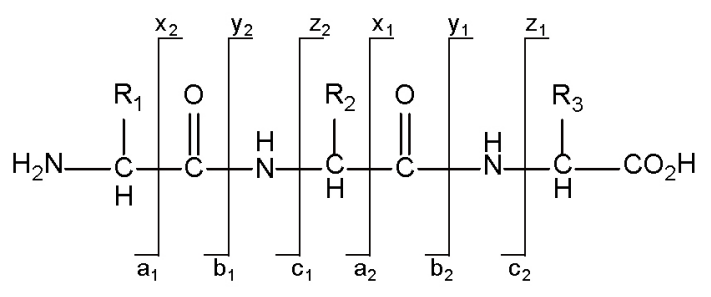

图 4 多肽二级质谱碎片离子示意图

用多维液相色谱-质谱联用方法研究顺铂与血清孵育 $3 \mathrm{~h}$ 后的蛋白质复合物, 发现顺铂在血清白蛋白上的 结合位点包括Cys34、Met329、Tyr150 (或Tyr148)和 Asp375 (或Glu376)残基. 利用自下而上质谱分析研究 蛋白质和金属药物复合物时, 一直存在肽段覆盖率低, 导致作用位点丢失的问题 ${ }^{[30,31,99]}$. 本课题组 ${ }^{[94,95,100]}$ 通 过选择合适的变性试剂, 采用硒代胱氨酸催化蛋白质 二硫键还原等方法, 显著改善了蛋白质, 特别是富含 二硫键蛋白质(如血清白蛋白(HSA)、转铁蛋白(Tf)) 的酶解效率, 使分析金属-HSA、金属-Tf复合物的肽 段覆盖率约增加到 $80 \%$, 大大提高了鉴定金属抗肿瘤 药物和蛋白质结合位点的鉴定效率. 由于一级质谱鉴 定的金属结合肽段可能同时含有几个能与金属结合 的氨基酸残基, 为了将金属结合位点确定到单个氨基 酸残基上, 在金属配合物和蛋白质反应前, 选择性地 将蛋白质暴露在溶剂中的组氨酸或蛋氨酸残基侧链 进行封闭, 然后, 通过蛋白质修饰前后金属结合肽段 信号强度的变化判断金属在蛋白质上的结合位点. 利 用该方法, 我们研究了有机金属钉抗肿瘤配合物 $\mathbf{1}$ 和 3 (图1)与人重组血清白蛋白 (rHA)的相互作用, 结果 显示, 两种钓配合物都能与血清白蛋白表面的组氨酸 残基His218、His247、His510和蛋氨酸残基Met298结 合, 但只有甲基异丙基苯配合物 1 能够进入含有半胱 氨酸残基Cys 34 的口袋内, 与Cys 34 的巯基结合, 并诱 导巯基氧化成亚磺酸基 ${ }^{\left[{ }^{[4]}\right.}$. 此前的高分辨FTICR-MS 研究表明, 有机金属钓配合物与 GSH中的放基配位诱 导颈基从分子氧或水中获得氧原子, 氧化为亚磺酰或 亚磺酸基 ${ }^{[101]}$. 颈基的氧化可能降低 $\mathrm{Ru}-\mathrm{S}$ 间的稳定性, DNA碱基能置换亚磺酰/亚磺酸基, 生成DNA-Ru复合 物 ${ }^{[22]}$. 鉴于颈基在蛋白质功能和活性发挥中的重要性, 这一结果意味着在缺氧的肿瘤细胞内, 水分子有可能 参与有机金属钓抗肿瘤配合物诱导的巯基氧化和钉 由结合到蛋白质到结合到DNA的转化过程. 结果还显
示, 含联苯配体的配合物 $\mathbf{3}$ 不能进入狭窄的口袋内与 Cys34结合, 表明芳烃配体的大小对于有机金属钉抗 肿瘤化合物与蛋白质的结合起着至关重要的作用.

二级质谱(MS/MS)分析是确认金属结合肽段上金 属结合位点的首选方法, 但研究发现, 在二级质谱的 碰撞诱导解离(CID)中, 钉化肽段上的 $\mathrm{Ru}-\mathrm{S} 、 \mathrm{Ru}-\mathrm{N}$ 键 在肽键之前断裂, 导致钉化位点丢失. 但是, $\mathrm{Pt}-\mathrm{N}$ 和 $\mathrm{Pt}-\mathrm{S}$ 配位键较 Ru-N、Ru-S 键强, 能在多肽的CID碎裂 中得以保留, 所以, 二级质谱分析可以将铂化位点确 定到单个氨基酸残基上. 利用二级质谱分析研究顺铂 与血清白蛋白结合产生的铂化肽段, 结果表明, 顺铂 除了能与蛋白表面的His128、His247和Met298残基结 合之外, 还能交联His67和His247两个组氨酸残基, 形 成交联蛋白复合物 ${ }^{[55]}$. 血清白蛋白是锌离子的转运蛋 白, His67和His 247 是锌离子在血清白蛋白上的主要结 合位点 ${ }^{[102]}$. 因而, 顺铂交联占据锌的结合位点, 可能干 扰血清白蛋白对锌离子的结合和转运. 这一发现为从 分子水平上解释顺铂的使用导致病人的低血锌和高 尿锌症状 ${ }^{[103]}$ 提供了可能的理论依据. 此外, 顺铂还能 诱导Cys124-Cys169二硫键的断裂, 并与还原的Cys 124 的䘪基共价结合. 该二硫键是维持血清白蛋白上血红 素、胆红素结合区域疏水性的关键化学键, 其诱导断 裂可能会影响血清白蛋白与血红素、胆红素的结合, 干扰它们的转运和代谢. 确切的生物学效应还要等待 进一步的研究.

转铁蛋白(transferrin, Tf ) 是人体血液中不可缺少 的生物分子, 在人血清中转铁蛋白的质量浓度为 2.5 $\mathrm{g} / \mathrm{L}$, 是血清中除血清白蛋白之外丰度最高的蛋白质. 转铁蛋白分为含铁(holo-Tf) 和不含铁(apo-Tf)两类, 含 铁蛋白约占 $30 \%$, 每个蛋白上能结合两个 3 价铁离子, 转铁蛋白向细胞内转运铁离子是通过转铁蛋白受体 (transferrin receptor, TfR)介导的内吞作用完成的, 而转 铁蛋白受体在很多肿瘤细胞上是高表达的 ${ }^{[104]}$. 转铁 蛋白也可以同许多金属化合物如 3 价钉、3价镓、铟 和 4 价钣等形成复合物 ${ }^{[104-108]}$, 这些金属-转铁蛋白复 合物依然可以被转铁蛋白受体所识别, 使通过转铁 蛋白受体介导的内吞作用向肿瘤细胞内定向输送金 属药物或诊断试剂成为可能 ${ }^{[109,110]}$. Dyson 等 ${ }^{[11]}$ 结合 胰蛋白酶酶解和LC-MS/MS研究转铁蛋白与顺铂的结 合位点, 发现顺铂与转铁蛋白的 Thr457氨基酸残基配 位. Thr457位于C-端铁离子结合位点口袋底部, 这个 
可能的结合位点也通过分子模拟得以证实. 但是在 Dyson等 ${ }^{[111]}$ 的研究中, 并未发现顺铂与Met256位点的 结合, 而这个位点是此前Sadler课题组 ${ }^{[12]}$ 利用NMR 鉴 定的顺铂与转铁蛋白的主要结合位点. Dyson等 ${ }^{[111]}$ 还 利用自下而上的质谱方法研究了钉化合物RAPTA-T 与转铁蛋白的相互作用, MS 分析发现, RAPTA-T可以 结合到 $\mathrm{K}_{239}$ DCHLAQVPSHTV ${ }_{251}$ 肽段上, 其中His249残 基参与了铁离子的结合, 但CID碎裂显示钉化合物结 合在His242而不是His249上. Sheldrick等 ${ }^{[31]}$ 利用二维 液相色谱-串联质谱研究顺铂与转铁蛋白的相互作用, 他们发现顺铂除与Thr457残基结合外, 还与Met256、

Glu265、Tyr314和Glu385残基结合. 不同课题组得到 有差异的结果可能是由于顺铂与转铁蛋白反应条件 的不同而造成, 如反应物摩尔比、反应时间、温度、 $\mathrm{pH}$ 等, 也有可能是分离方法而引起. 二维液相色谱能 更好地分离和富集铂化肽段, 从而提高质谱的分析效 率, 获得更多的结合位点信息. 本课题组也利用LC-MS 方法, 结合分子模拟计算, 以顺铂作为对照, 研究了在 模拟生理条件下, 有机金属钉抗肿瘤化合物 1 和 3 与 人源转铁蛋白的共价相互作用 ${ }^{[100]}$. 我们发现, 两种钉 化合物无论是与含铁或不含铁的转铁蛋白反应, 都倾 向于与蛋白表面裸露的组氨酸残基His242、His273、 His578和His606共价结合; 但顺铂除了与含铁或不含 铁的转铁蛋白中的His273、His578结合外, 还能与表 面裸露的Tyr136、Tyr317、Met256残基配位. 除此之 外, 也发现顺铂还能与不含铁的转铁蛋白 C-端铁离子 结合口袋底部的 $T h r 457$ 残基结合 ${ }^{[100]}$.

铜伴侣蛋白(copper chaperon protein)是在动植物、 细菌及人体内均存在的一类蛋白质, 它们在细胞内执 行双重功能, 即运输铜和防止铜离子暴露于胞质 ${ }^{[113]}$. 大量研究表明, 人体内的铜转运系统蛋白质参与了顺 铂的作用过程, 影响顺铂的细胞毒性和抗药性 ${ }^{[93,114]}$. 人 铜伴侣蛋白Atox 1 由 68 个氨基酸残基构成, 具有维持细 胞内铜离子的平衡功能 ${ }^{[115]}$, 已有研究表明, 顺铂能够与 Atox 1 上铜离子的结合位点结合 ${ }^{[116,117]}$. 本课题组与中 国科技大学刘扬中课题组 ${ }^{[118,119]}$ 合作, 综合应用NMR、 自下而上质谱分析研究了顺铂和两种具有抗癌活性 的反铂类化合物 (trans- $\left[\mathrm{PtCl}_{2}\left\{\mathrm{E}-\mathrm{HN}=\mathrm{C}\left(\mathrm{OCH}_{3}\right) \mathrm{CH}_{3}\right\}_{2}\right]$ 、 trans-EE和trans- $\left[\mathrm{PtCl}_{2}\left(\mathrm{NH}_{3}\right)\right.$ (thiazole) $]$ 、trans-PtTz) 与 Atox 1 的相互作用, 对有机金属钓化合物 $\mathbf{1}$ 和 $\mathbf{3}$ 与Atox 1 的反应也进行了初步探索. 结果表明, 在有 $\mathrm{Cu}^{+}$和无
$\mathrm{Cu}^{+}$共存条件下, 5 种金属配合物与Atox 1 的结合形式基 本相同, 均能与铜离子结合位点Cys 12 和Cys 15 残基结 合. 我们还发现, $\mathrm{Cu}^{+}$的存在加快顺铂、反铂化合物与 Atox 1的反应, 对钓化合物与Atox 1的结合没有明显影 响. 此外, 5 种金属配合物的结合促进蛋白聚集的程度 各异, 顺铂相比其他4种金属配合物更容易促进蛋白 二聚体的生成. 在顺铂与Atox 1 的反应过程中, 顺铂分 子中氨基配体的离去加快铂与Atox 1的配位结合, 并 且加快分子间交联产物的生成. 结合了顺铂的Atox 1 的聚集可能是细胞对顺铂产生抗药性的原因之一 ${ }^{[116]}$. 两种反铂配合物及两种有机金属钓配合物在与Atox 1 的反应过程中, 配体基团非常稳定, 很难从化合物分 子上离去, 分子间交联产物的生成较少. 这些研究结 果表明, 金属抗肿瘤配合物与Atox 1 反应机制的不同 将会对相应金属配合物在细胞中的代谢过程产生不 同性质的影响.

人细胞色素氧化酶的组装蛋白 17 (Cox17)也是一 种铜伴侣蛋白, 它负责将 $\mathrm{Cu}^{+}$转运到线粒体中 ${ }^{[120]}$. Cox17 含有 6 个半胱氨酸残基, 根据形成二硫键的个数可有 3 种不同的氧化态, 即 Cox $17_{1 s-s} 、 \operatorname{Cox} 17_{2 \mathrm{ss}-\mathrm{s}}$ 和 Cox $17_{3 \mathrm{~s}-\mathrm{s} \text {. }}$. 其中, Cox $17_{2 \mathrm{~s}-\mathrm{s}}$ 是功能化态, 负责将铜离子转移到线粒 体膜间隙 (intermembrane space $)^{[121]}$. 刘扬中等 ${ }^{[122]}$ 利用 NMR、ESI-MS和光谱等技术研究了顺铂与 Cox 17 的 相互作用, 发现Cox17能将顺铂转运到线粒体中, 其结 合位点应该是铜离子结合位点中的半胱氨酸巯基, 并 且能将铜离子竞争下来. 他们还发现顺铂与 $\mathrm{Cu}^{+}-\mathrm{Cox} 17$ 的反应活性比顺铂与apo-Cox17的反应活性高, 其中可 能的原因是 $\mathrm{Cu}^{+}-\mathrm{Pt}$ 在铂化产物形成中发生相互作用的 缘故. 本课题组 ${ }^{[123]}$ 则利用自下而上的质谱方法, 对比 研究了顺铂和有机金属钉抗肿瘤化合物 1 和 3 与 Cox 17 的反应. 结果表明, 虽然顺铂与有机金属钉化合物在 Cox17上结合位点相同(Met4、Cys27/Cys26和His47), 但顺铂与Cox17的反应活性要比有机金属钉化合物与 Cox17的反应活性高得多. 质谱分析可获得单铂化到 四铂化的Cox 17 的多电荷质谱峰, 但是在同样的反应 比例下钓化合物与Cox17反应的主要产物是单钓化的 金属-蛋白质复合物及少量双钓化的产物. CD光谱显 示顺铂对Cox17蛋白质构型的破坏要比两种有机金属 钓配合物大得多,表明Cox17 可能并没有参与有机金 属钓抗肿瘤配合物的作用过程.

谷胱甘肽转移酶(GST) 是与肿瘤细胞抗药性相关 
的含颈基的活性物质. 这类酶能够催化疏水性较强的 药物分子偶联上亲水性强的还原型谷胱甘肽 $(\mathrm{GSH})$, 使 药物分子亲水性增加, 进而在消耗ATP的情况下, 将药 物排出细胞, 这也是GST 导致抗药性的机制 ${ }^{[124]}$. GST 有很多类型, 其中 $\mathrm{GST} \pi$ 在多种癌细胞中都高表达 ${ }^{[125]}$, 所以, 特异性的GST $\pi$ 抑制剂也成为肿瘤靶向药物设计 的方向. 我们利用自下而上的质谱方法, 比较研究了 有机金属钓配合物 $1 、 3 、 4$ 和 GST $\pi$ 的相互作用及作 用位点 ${ }^{[126]}$ 发现, 3 种有机金属钓配合物都能结合在位 于 G-site上的Cys 15 和Cys 48 , 以及位于二聚体界面上 的Cys 102 和Met92残基上, 并诱导半胱氨酸残基上巯 基氧化为亚磺酰基. 其中, Cys 15 和Cys 48 位点是 GST $\pi$ 底物GSH的结合区, Cys102和Met92则属于二聚化区, 钓配合物与这些残基的结合会干扰GST $\pi$ 的功能, 是 抑制GST $\pi$ 催化活性的原因. 3 种钓配合物抑制GST $\pi$ 的 $\mathrm{IC}_{50}$ 值分别是 $59.4 \pm 1.3 、 63.2 \pm 0.4$ 和 $37.2 \pm 1.1 \mu \mathrm{M}$, 它 们对GST $\pi$ 不同程度抑制的原因可能是配合物的芳香 配基不同.

自下而上的质谱分析必须将蛋白质-金属药物复 合物先酶解成肽段, 肽段混合物经液相色谱分离, 进 行在线的质谱检测, 鉴定金属化的肽段 ${ }^{[127]}$. 蛋白质或 蛋白质复合物的酶解是一个耗时的过程, 其中涉及 使用高浓度的变性剂、还原剂, 由此可能导致金属蛋白质配位键的解离, 使金属-蛋白质结合信息丢失 (表1 $)^{[111,126]}$. 所以, 自上而下的质谱分析方法也在研究 金属药物与蛋白质的相互作用领域得到青睐. 自上而 下的质谱分析直接针对蛋白质-金属复合物, 先利用 ESI-MS或MALDI-MS分析, 鉴定金属-蛋白质复合物 的质谱信号, 再以确认的金属-蛋白质离子为母离子, 以 CID、红外多光子解离(IRMPD)、 $\mathrm{ECD}$ 等技术将全 蛋白裂解, 分析鉴定含金属药物的碎片离子, 获得药 物在蛋白上的结合位点信息 ${ }^{[128,129]}$. 自上而下的质谱方 法的优点是, 样品不需要经过酶解等前处理步骤, 能 够最大限度地保留金属药物和蛋白质结合的结构信 息(表1).

Hartinger 等 ${ }^{[130]}$ 基于自上而下策略, 利用电 喷雾电离傅里叶变换离子回旋共振串联质谱 (ESI-FTICR-MS/MS) 研究了顺铂、奥沙利铂、反铂 与泛素的相互作用. CID裂解获得的碎片离子显示, 顺铂和奥沙利铂结合在泛素 $\mathrm{N}$ 端的Met1残基上, 而 反铂则可能结合在His68残基上. 他们还发现, CID
和IRMPD裂解方法都能获得含铂的蛋白碎片离子, 但使用 ECD裂解方法却没有发现含铂片段, 可能的 原因是由于铂离子捕获电子, 使产生的含铂片段中 性化, 不能被质谱检测 ${ }^{[131]}$. 但是, O'Connor 等 ${ }^{[96,132]}$ 利用 ECD裂解, 结合高分辨FTICR-MS/MS 质谱检 测到顺铂、 $[\mathrm{Pt}(\mathrm{dien}) \mathrm{Cl}] \mathrm{Cl}$ 和 $\left[\left(\eta^{5}-\mathrm{C}_{5} \mathrm{Me}_{5}\right) \mathrm{Ir}(\mathrm{phpy}) \mathrm{Cl}\right]$ 、 $\left[\left(\eta^{5}-\mathrm{C}_{5} \mathrm{Me}_{4} \mathrm{C}_{6} \mathrm{H}_{4} \mathrm{C}_{6} \mathrm{H}_{5}\right) \mathrm{Ir}-(\mathrm{phpy}) \mathrm{Cl}\right]$ 与钻调蛋白 (calmodulin)复合物产生的 $\mathrm{M}^{*}$-Met碎片离子, 显示Pt、Ir对钙 调蛋白甲硫氨酸残基的亲和性. 进一步的自上而下的 质谱研究表明, 顺铂能通过交联蛋白上的Met残基, 形 成蛋白交联复合物 ${ }^{[132]}$. 在应用自上而下ECD质谱分析 研究顺铂和Cox17蛋白的作用位点时, 检测到Pt结合 在 $\mathrm{K}_{24} \mathrm{PCCACPET}_{32}$ 片段上的碎片离子 ${ }^{[133]}$, 也证实 $\mathrm{ECD}$ 裂解可以获得金属-蛋白质残基碎片离子. 根据顺铂对 不同氨基酸残基的亲和性, 推测这个片段上的Cys 26 或Cys27可能是顺铂的结合位点, 与之前自下而上的 质谱分析获得的结果一致 ${ }^{[123]}$. Gómez-Gómez等 ${ }^{[134]}$ 利 用线性离子阱(ESI-LIT)-MS/MS研究了胰岛素和顺铂 之间的相互作用. 胰岛素同样是一个小蛋白,含有2条 由一个分子内二硫键联接的肽链. 胰岛素与顺铂反应 最多可以结合 3 个顺铂分子. 利用 CID裂解和多级质 谱 $\left(\mathrm{MS}^{n+}\right)$ 分析发现, 顺铂主要结合在肤岛素B链 $\mathrm{N}$ 端的 His5 和His 10残基上. 研究结果还显示, 顺铂也可能结 合在Cys7残基上, 虽然该残基在蛋白中形成了二硫键. 金属硫蛋白(metallothionein, MT)富含半胱氨酸残基, 可能是顺铂在细胞内结合的重要蛋白分子. 本课题 组 ${ }^{[135]}$ 利用MALDI-TOF-MS研究了顺铂和金属硫蛋白 在酸性和中性条件下的反应, 发现在酸性条件下顺铂 的反应活性更高, 最多有 5 个顺铂分子结合在金属硫蛋

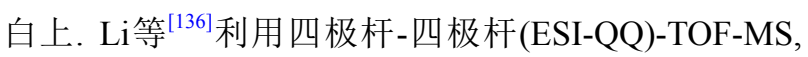
结合CID裂解研究了金属硫蛋白与顺铂的结合位点, 发现顺铂主要结合在Cys5和Cys7残基上.

\section{4 质谱定量研究金属抗肿瘤化合物与蛋白 质的相互作用}

电感耦合等离子体质谱(ICP-MS)是一种元素质谱 定量分析技术. 通过在高达 $10000^{\circ} \mathrm{C}$ 高温ICP炬中的热 解反应, 分析物裂解为气态原子, 并进一步激发电离产 生元素离子, 通过质量分析器分离, 可检测分析物组 成元素的质荷比信号, 对元素离子进行绝对定量分析. ICP-MS具有灵敏度高、线性范围宽、分析速度快、 
多元素同时测定及同位素分辨等优点, 已成为痕量元 素分析中一种主要的检测手段 ${ }^{[137 \sim 139]}$, 对金属元素的 检测限可达 ppm $(\mathrm{pg} / \mathrm{mL})$ 级, 特别适合金属药物-蛋白 质复合物的定量分析. ICP-MS能同时获得金属和蛋白 质硫元素的定量信息 ${ }^{[140]}$, 其与各种色谱分离技术联用 已被广泛用于金属-蛋白质复合物的定量分析 ${ }^{[141]}$. 例 如, 体积排阻柱(SEC)-HPLC-ICP-MS结合柱后同位素 稀释法定量分析顺铂和MT结合化学计量比 ${ }^{[142]}$, 结果 表明, 顺铂可定量取代MT结合的Zn离子, 但不能取代 在同一位点结合的Cd离子. Sadler等 ${ }^{[143]}$ 用ICP-MS精确 测量了转铁蛋白-顺铂复合物溶液中铂的浓度, 检测限 可达 $0.03 \mu \mathrm{g} / \mathrm{L}$. Keppler、Szpunar、Hartinger及其合作 者在ICP-MS与色谱(HPLC、毛细管电泳 $(C E))$ 等技术 联用定量研究金属药物与蛋白质相互作用方面做了大 量工作 ${ }^{[27,28,144-147]}$, 他们将HPLC与ICP-MS联用研究了 顺铂与人血清蛋白的反应动力学 ${ }^{[148]}$, 反应 $3 \mathrm{~h}$ 后没有检 测到铂-蛋白质复合物, $80 \%$ 的药物仍然是自由态, 这 比之前报道的顺铂与血清蛋白的反应活性低. 他们应 用CE-ICP-MS研究的结果表明, 当顺铂/血清白蛋白摩 尔比增加时, 反应速率明显增加 ${ }^{[199]}$. 在 20 倍过量顺铂 浓度下, 反应速率达到最大值, 反应 $50 \mathrm{~h}$ 后每一个血清 白蛋白结合 10 个铂原子. 按照准一级反应计算的反应 速率常数 $(k)$ 为 $5.5 \times 10^{-5} \mathrm{~s}^{-1}$. 3 价钓候选药物 KP1019水 溶性差 ${ }^{[150]}$, 制成钠盐(KP1339) 时水溶性得以改善. 但 Keppler等 ${ }^{[151]}$ 利用CE-ICP-MS研究KP1019和KP1339与 HSA 和Tf的反应时, 发现两种化合物与两种蛋白的反 应速率基本相似. Dyson等 ${ }^{[152]}$ 利用 SEC-HPLC-ICP-MS 和ESI-MS研究了有机金属钉化合物RAPTA-T和顺铂 与holo-Tf、apo-Tf和HSA的相互作用, 发现顺铂与 3 种 蛋白的结合比在 $0.2 \sim 0.35 \mathrm{~mol}(\mathrm{pt}) / \mathrm{mol}$ (蛋白质)之间; 而RAPTA-T对holo-Tf的亲和力最高, 每个蛋白分子上 可以结合 1.4 个钉原子; RAPTA-T对apo-Tf和HSA的亲 和性也比顺铂高, 每个蛋白复合物分子结合 $0.5 \sim 1.0$ 个 钉原子. RAPTA-T对holo-Tf较高的亲和力表明, 铁离 子的存在有助于钉化合物与 Tf的结合. Mandal等 ${ }^{[153]}$ 也应用SEC-HPLC-ICP-MS实时监测了铂类化合物(顺 铂、卡铂和奥沙利铂) 和血红蛋白反应产物中 ${ }^{57} \mathrm{Fe}$ 和 ${ }^{195} \mathrm{Pt}$ 的摩尔比. 结果显示, 奥沙利铂和顺铂与血红蛋白 的反应活性相似, 其结合导致铁血红素从蛋白上部分 解离. 尽管卡铂与血红蛋白的结合也能引起铁血红素 的部分解离, 但与顺铂和奥沙利铂相比, 卡铂与血红
蛋白的反应活性要低得多. 他们还综合应用纳升喷雾 Q-TOF-MS和SEC-HPLC-ICP-MS表征了顺铂和兔源金 属硫蛋白(MT)的反应产物. 兔源金属硫蛋白含 $1.4 \%$ 的 锌和 $7.9 \%$ 的镉. 他们的结果显示在中性条件下, 顺铂 能置换结合在半胱氨酸残基上的锌, 与镉结合在同一 蛋白分子上, 形成 $\mathrm{Cd}_{4}-\mathrm{Pt}_{n}-\mathrm{MT}(n=1 \sim 7)$ 产物. 这与此前 文献报道的结果, 即顺铂不能取代金属硫蛋白结合的 镉的结论是一致的. 另一方面, 金属硫蛋白能结合顺 铂, 可能与细胞对顺铂的抗药性有关 ${ }^{[154]}$.

虽然ICP-MS测定蛋白质分子中金属元素的丰度 具有极高的灵敏度, 但由于其测定的是总蛋白结合金 属的化学计量比, 很难确定结合在特定氨基酸残基上 的金属元素的量. 在ESI-MS和MALDI-MS分析中, 由 于金属的结合对蛋白质或多肽离子化效率影响的不 确定性, 不能简单地通过比较金属药物-蛋白质复合物 或金属药物-多肽复合物的质谱信号强度, 定量表征金 属药物与蛋白质结合的化学计量比. 而金属化多肽标 准品的缺乏, 使通过内标(或外标)自下而上质谱分析 定量测定金属化多肽几乎不可能. 所以, 应用ESI-MS 和MALDI-MS定量表征金属药物结合在蛋白质特定 氨基酸残基上的计量比是一个颇具挑战性的课题. 本 课题组基于定量蛋白质组学分析中稳定同位素标记 技术, 发展了一种稳定同位素标记和LC-ESI-MS相结 合的方法, 实现了金属抗肿瘤配合物与蛋白质特定氨 基酸残基结合计量比的定量测定 ${ }^{[118,119,155]}$. 如图5所示, 将等摩尔比的蛋白质和蛋白质-金属药物复合物分别 以胰蛋白酶酶解, 将“轻标”和 “重标”同位素试剂, 如 乙酸- $N$-琥珀酰亚胺酯 ( $N$-acetoxysuccinimide, NAS) 和 $N$-乙基马来酰亚胺 $(N$-ethylmaleimide, NEM) 分别加入 到蛋白质和蛋白质-金属复合物的酶解混合物中, 化 学标记酶解肽段; 轻同位素试剂标记的肽段为“轻肽”, 重同位素标记的肽段为“重肽”; 然后, 将“轻肽”和“重 肽”按 $1: 1$ 体积混合, 进行LC-MS分析, 通过比较同一条 轻/重标记肽段的质谱信号, 两者信号相等即表明对 应的肽段没有和金属药物反应; 如两者信号有显著差 异, 其信号强度差即对应这条肽段与金属药物结合的 比例. NAS 是一种针对肽段末端和侧链上氨基 $\left(-\mathrm{NH}_{2}\right)$ 的特异性标记试剂, 能定量与氨基通过缩合反应, 生 成稳定的酰胺化合物. NAS带有 3 个标记同位素(H-D), 每一个标记试剂将给轻重标记的肽段引入 3 个质量数 (Da)的差异, 质谱分析可以灵敏地区分轻重标记肽段 

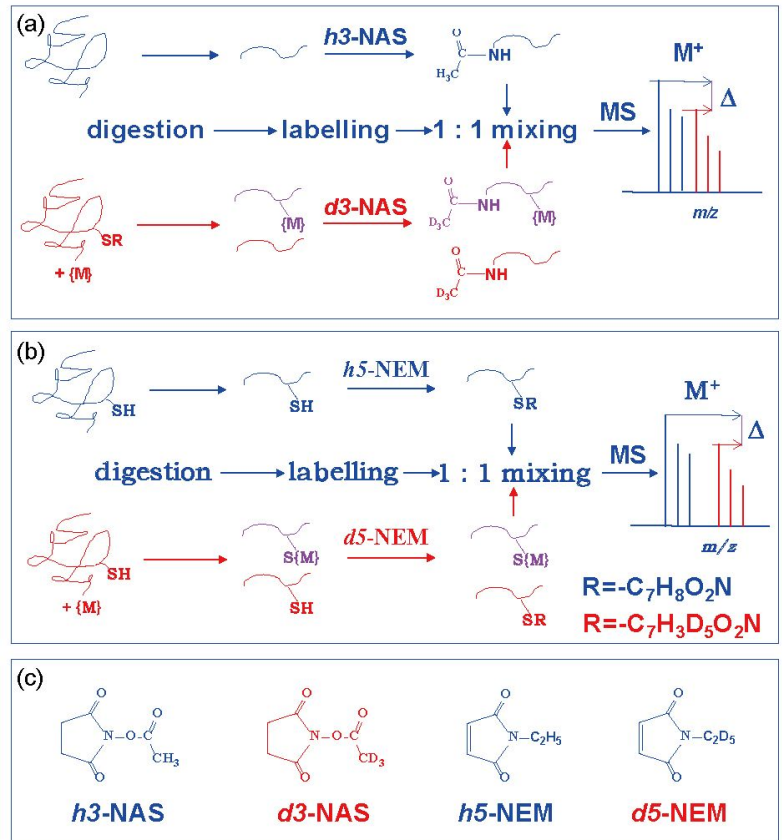

图 5 基于稳定同位素标记的ESI-MS 定量分析金属药物与 蛋白质结合计量比的流程示意图. (a) 针对多肽氨基 $\left(-\mathrm{NH}_{2}\right)$ 的同位素标记方法; (b) 针对多肽颈基(-SH)的同位素标记方 法; (c) 同位素标记试剂 $N$-乙酸琥珀酰亚胺(NAS) 和 $N$-乙基 马兰酰亚胺(NEM) (网络版彩图)

(图5(a)). 应用NAS标记方法, 通过LC-MS分析, 定量测 定了 3 种有机金属钓抗肿瘤配合物 $1 、 3$ 和 4 (图1)与谷 胱甘肽转移酶 GST $\pi$ 结合计量比 ${ }^{[155]}$. 之前的自下而上的 质谱分析表明, 3 种钓配合物都能与 GST $\pi$ 上的Cys 15 、 Cys48、Met92和Cys102结合 ${ }^{[126]}$. 定量分析结果表明, 3 种钓配合物都对Met92表现高反应活性, 对Cys48和 Cys 15 的反应活性次之, 对Cys 102 的活性最低. 因为 3 种化合物在有、无GSH存在时, 对GST $\pi$ 的抑制活性 几乎不变, 但在 GSH存在时, 他们与Met 92 和Cys 102 的 结合急剧减少, 所以, 3 种配合物和Cys 15 和Cys 48 的结 合是它们抑制GST $\pi$ 活性的主要原因. Cys 15 和Cys 48 都是位于 GST $\pi$ 分子中 $\mathrm{G}$-site, 即 GSH结合域内的残基, 钓配合物的结合会干扰GST $\pi$ 与 GSH的结合, 所以抑制 $\mathrm{GST} \pi$ 的催化活性. 我们的这一结果说明, 定量表征金 属配合物与蛋白质(或酶)的相互作用, 将有助于进一 步理解他们的分子作用机理.

$N$-乙基马来酰亚胺 (NEM) 是一种针对蛋白质颈 基的特异性标记试剂, 通过亲核加成的方式和颈基 反应, 生成硫醚衍生物 ${ }^{[156]}$. NEM含有 5 个同位素置换
的 $\mathrm{H}$ 原子(H-D), 标记一个颈基将给轻重标记肽段引入 5 个质量数的差异. 基于NEM同位素标记技术, 应用 LC-ESI-MS定量研究了钉/铂抗肿瘤配合物与蛋白质 Atox 1、过氧化物氧化还原酶I (Prx-I)的巯基(功能)催 化位点的配合反应 ${ }^{[155]}$. 定性研究结果表明 ${ }^{[118,119]}$, 顺铂 能与Atox 1 中 $\mathrm{Cu}^{+}$的结合位点Cys 15 和Cys 18 结合, 而且 $\mathrm{Cu}^{+}$可以加快 $\mathrm{Pt}$ 与颈基的结合. 定量分析结果表明, 在 没有 $\mathrm{Cu}^{+}$存在时, 顺铂能与蛋白中 $13.5 \%$ 的Cys $15 / \mathrm{Cys} 18$ 发生反应; 而在 $\mathrm{Cu}^{+}$存在下, 相同反应时间内顺铂结合 Cys 15/Cys18的比例达到 $50.3 \%$. 这一结果给 $\mathrm{Cu}^{+}$能促进 顺铂与Atox 1 颈基的结合提供了直接的证据 ${ }^{[118]}$. NEM 标记除了可以定量分析金属药物与蛋白质颈基的反 应计量比之外, 还可以在一个肽段含有多个颈基的情 况下, 结合串联质谱, 不需要再借助其他化学修饰试 剂, 同时实现对颈基结合位点的定性鉴定. 定量分析 的结果直接证明, 顺铂可以占据 $\mathrm{Cu}^{+}$的结合位点, 结合 Atox1上的Cys15、Cys18形成交联复合物 ${ }^{[118,119]}$. NEM 标记技术还被用于LC-MS定量研究有机金属钓抗肿 瘤配合物 $1 、 2$ 和 4 与Prx-I颈基催化位点的结合计量 比. 结果表明, 3 种钓配合物都能与Prx-I的共催化位点 Cys173结合, 并诱导颈基氧化为亚磺酰基, 而配合物 $\mathbf{2}$ 与Cys173的反应活性最高, 与其抑制Prx-I活性最好相 一致.

\section{5 展望}

尽管DNA被认为是传统细胞毒性金属抗肿瘤药 物的终极靶标, 但是一方面金属药物对蛋白质的亲和 性使药物与蛋白质的相互作用不可避免, 这种作用不 仅在很大程度上影响金属药物的生物利用度, 而且与 金属药物的毒副作用以及肿瘤细胞抗药性的产生密 切相关. 另一方面, 最近的研究表明, 金属药物与蛋白 质的相互作用可能在其活性发挥中扮演重要角色, 或 通过协同作用, 增强细胞毒性金属抗肿瘤药物的活性. 所以, 研究金属药物与蛋白质的相互作用和研究药物 与DNA的相互作用同等重要.

基于软电离技术的质谱分析, 能够在检测过程中 保留金属抗肿瘤药物与蛋白质的共价(配位)结合, 甚 至较强的非共价结合信息. 而质量分析器的发展也大 大提高了质谱分析的质量分辨率, 为生物活性分子, 特 别是生物大分子及其复合物的分析鉴定提供了更为 快速、准确和灵敏的技术. 但是, 目前大部分药物分 
子作用机理的的研究都是在模拟生理条件下将蛋白 质或肿瘤细胞与金属药物捊育, 而为了提高反应中生 成金属药物-蛋白质复合物的比率, 通常金属药物都是 大大过量于蛋白质, 不能真实地反映药物在人体内作 用过程的真实情况. 而且, 大剂量药物与细胞孵育会 导致细胞异常的应激反应, 使药物与蛋白质或DNA的 作用出现偏离, 导致假阳性、假阴性结果的产生. 因 此, 临床剂量条件药物分子作用机理研究面临着实际 样品组成复杂及金属药物-蛋白质(DNA)复合物含量 极低的挑战. 要解决这些问题, 可以充分发挥ICP-MS 和ESI-MS各自的优势, 利用 $1 \mathrm{D}$ 或2D色谱分离技术和 质谱联用技术分析血液、组织或细胞等复杂(临床)生 物样品, 鉴定与金属药物结合的生物靶分子, 表征药 物分子与靶分子结合的化学计量比. 另外, 发展针对 性的分离富集方法, 从实际生物样品中选择性富集结 合金属药物的低丰度蛋白质和DNA复合物, 再应用自 下而上或自上而下的质谱方法分析鉴定金属药物在 生物靶分子上的结合位点和作用方式. 目前, 自上而 下的质谱分析方法主要应用于小分子量的蛋白质-金
属、DNA-药物复合物的结构鉴定, 随着质谱分析质 量分辨率的提高、解离技术的发展和完善,应用自上 而下的质谱分析研究大分子量蛋白质(DNA)-药物复 合物指日可待。

细胞、组织和人体是非常复杂的生物体系, 如果 单纯从化学角度在体外研究抗肿瘤化合物与生物靶分 子的作用, 建立药物的构效关系, 由此篎选和发现的先 导化合物可能进入体内试验时并不能产生预期的生 物活性. 所以未来药物作用机理的研究必须更多的需 要与临床生物医学家、药学家合作 ${ }^{[157,158]}$, 探索药物在 体内的作用机制, 实现药物早期的成药性和安全性评 价, 这样才能更好地提高药物发现的成功率. 近年来飞 速发展的质谱成像技术, 包括激光烧蚀(LA)-ICP-MS 成像、MALDI-MS成像和二次离子质谱成像, 可以在 微、纳米空间分辨率下, 从组织到单细胞水平上研究 金属药物在体内的靶向传输、代谢和细胞摄入、分 布等 ${ }^{[159168]}$, 将在金属抗肿瘤药物成药性、安全性评 价,药物代谢动力学研究、分子作用机理研究等领域 得到越来越多的应用.

\section{参考文献}

Rosenberg B, van Camp L, Krigas T. Nature, 1965, 205: 698-699

2 Rosenberg B, Vancamp L, Trosko JE, Mansour VH. Nature, 1969, 222: 385-386

3 Boulikas T, Vougiouka M. Oncol Rep, 2004, 11: 559

Brabec V, Kasparkova J. Drug Resis Updates, 2005, 8: 131-146

Wang D, Lippard SJ. Nat Rev Drug Discov, 2005, 4: 307-320

Bruijnincx PCA, Sadler PJ. Adv Inorg Chem, 2009, 61: 1-62

Hartinger CG, Dyson PJ. Chem Soc Rev, 2009, 38: 391-401

Jakupec MA, Galanski M, Arion VB, Hartinger CG, Keppler BK. Dalton Trans, 2008, 2008: 183-194

Sava G, Bergamo A, Dyson PJ. Dalton Trans, 2011, 40: 9069

Kapitza S, Jakupec MA, Uhl M, Keppler BK, Marian B. Cancer Lett, 2005, 226: 115-121

1 Kapitza S, Pongratz M, Jakupec MA, Heffeter P, Berger W, Lackinger L, Keppler BK, Marian B. J Cancer Res Clin Oncol, 2005, 131: 101-110

Rademaker-Lakhai JM, van den Bongard D, Pluim D, Beijnen JH, Schellens JHM. Clinic Cancer Res, 2004, 10: 3717-3727

Clarke MJ. Metal Ions Biol Sys, 1980, 11: 231-283

4 Clarke MJ, Bitler S, Rennert D, Buchbinder M, Kelman AD. J Inorg Biochem, 1980, 12: 79-87

5 Melchart M, Sadler PJ. In: Jaouen G, Ed. Bioorganometallics: Biomolecules, Labeling, Medicine. Weinheim: Wiley-VCH, 2006

6 van Rijt SH, Sadler PJ. Drug Discov Today, 2009, 14: 1089-1097

17 Yan YK, Melchart M, Habtemariam A, Sadler PJ. Chem Commun, 2005, 38: 4764

18 Chatterjee S, Kundu S, Bhattacharyya A, Hartinger CG, Dyson PJ. J Biol Inorg Chem, 2008, 13: 1149-1155

19 Scolaro C, Chaplin AB, Hartinger CG, Bergamo A, Cocchietto M, Keppler BK, Sava G, Dyson PJ. Dalton Trans, 2007, 2007: 5065

20 Vock CA, Ang WH, Scolaro C, Phillips AD, Lagopoulos L, Juillerat-Jeanneret L, Sava G, Scopelliti R, Dyson PJ. J Med Chem, 2007, 50: 2166-2175

21 Ang WH, Dyson PJ. Eur J Inorg Chem, 2006, 2006: 4003 

IDH, Jodrell DI, Parsons S, Sadler PJ. Proc Natl Acad Sci USA, 2005, 102: 18269-18274

Jung Y, Lippard SJ. Chem Rev, 2007, 107: 1387-1407

Johnstone TC, Suntharalingam K, Lippard SJ. Chem Rev, 2016, 116: 3436-3486

Wang X, Guo Z. Chem Soc Rev, 2013, 42: 202-224

Hartinger CG, Groessl M, Meier SM, Casini A, Dyson PJ. Chem Soc Rev, 2013, 42: 6186-6199

Timerbaev AR, Hartinger CG, Aleksenko SS, Keppler BK. Chem Rev, 2006, 106: 2224-2248

Will J, Kyas A, Sheldrick WS, Wolters D. J Biol Inorg Chem, 2007, 12: 883-894

Will J, Sheldrick WS, Wolters D. J Biol Inorg Chem, 2008, 13: 421-434

Will J, Wolters DA, Sheldrick WS. ChemMedChem, 2008, 3: 1696-1707

Timerbaev AR. J Anal Atom Spectrom, 2014, 29: 1058

Jamieson ER, Lippard SJ. Chem Rev, 1999, 99: 2467-2498

Suntharalingam K, Mendoza O, Duarte AA, Mann DJ, Vilar R. Metallomics, 2013, 5: 514-523

Berners-Price SJ, Ronconi L, Sadler PJ. Prog Nucl Mag Res Sp, 2006, 49: 65-98

Hambley TW. J Chem Soc Dalton Trans, 2001, 2001: 2711-2718

Ronconi L, Sadler PJ. Coord Chem Rev, 2008, 252: 2239-2277

Sirajuddin M, Ali S, Badshah A. J Photochem Photobiol B, 2013, 124: 1-19

Brabec V, Vrana O, Boudny V. Prog Biophys Mol Biol, 1996, 65: Pb113

Reedijk J. Eur J Inorg Chem, 2009, 2009: 1303-1312

Vinje J, Sletten E. Anti-Cancer Agent Med Chem, 2007, 7: 35-54

Lippard SJ. Pure Appl Chem, 1987, 59: 731-742

Lippert B. Biometals, 1992, 5: 195-208

Sherman SE, Lippard SJ. Chem Rev, 1987, 87: 1153-1181

Takahara PM, Rosenzweig AC, Frederick CA, Lippard SJ. Nature, 1995, 377: 649-652

Chen H, Parkinson JA, Morris RE, Sadler PJ. J Am Chem Soc, 2003, 125: 173-186

Chen H, Parkinson JA, Parsons S, Coxall RA, Gould RO, Sadler PJ. J Am Chem Soc, 2002, 124: 3064-3082 $14623-14628$

Liu HK, Wang F, Parkinson JA, Bella J, Sadler PJ. Chem Eur J, 2006, 12: 6151-6165

Liu HK, Parkinson JA, Bella J, Wang F, Sadler PJ. Chem Sci, 2010, 1: 258-270

Novakova O, Chen H, Vrana O, Rodger A, Sadler PJ, Brabec V. Biochemistry, 2003, 42: 11544-11554

Beck JL, Colgrave ML, Ralph SF, Sheil MM. Mass Spectrom Rev, 2001, 20: 61-87

Triolo A, Arcamone FM, Raffaelli A, Salvadori P. J Mass Spectrom, 1997, 32: 1186-1194

Wang B, Sayer JM, Yagi H, Frank H, Seidel A, Jerina DM. J Am Chem Soc, 2006, 128: 10079-10084

Gupta R, Beck JL, Sheil MM, Ralph SF. J Inorg Biochem, 2005, 99: 552-559

Gonnet F, Kocher F, Blais JC, Bolbach G, Tabet JC, Chottard JC. J Mass Spectrom, 1996, 31: 802-809

Barry CG, Baruah H, Bierbach U. J Am Chem Soc, 2003, 125: 9629-9637 Chem, 2001, 44: 3616-3621

Wu K, Luo Q, Hu W, Li X, Wang F, Xiong S, Sadler PJ. Metallomics, 2012, 4: 139-148

Téletchéa S, Skauge T, Sletten E, Kozelka J. Chem Eur J, 2009, 15: 12320-12337

del Socorro Murdoch P, Guo Z, Parkinson JA, Sadler PJ. J Biol Inorg Chem, 1999, 4: 32-38

Gaucheron F, Malinge JM, Blacker AJ, Lehn JM, Leng M. Proc Natl Acad Sci USA, 1991, 88: 3516-3519

Johnson NP, Mazard AM, Escalier J, Macquet JP. J Am Chem Soc, 1985, 107: 6376-6380

Aird RE, Cummings J, Ritchie AA, Muir M, Morris RE, Chen H, Sadler PJ, Jodrell DI. Brit J Cancer, 2002, 86: 1652-1657

Wu Y, Pradhan P, Havener J, Boysen G, Swenberg JA, Campbell SL, Chaney SG. J Mol Biol, 2004, 341: 1251-1269

Fichtinger-Schepman AMJ, Van der Veer JL, Den Hartog JHJ, Lohman PHM, Reedijk J. Biochemistry, 1985, 24: 707-713

Chen H, Parkinson JA, Nováková O, Bella J, Wang F, Dawson A, Gould R, Parsons S, Brabec V, Sadler PJ. Proc Natl Acad Sci USA, 2003, 100:

Liu HK, Berners-Price SJ, Wang F, Parkinson JA, Xu J, Bella J, Sadler PJ. Angew Chem Int Ed, 2006, 45: 8153-8156

Novakova O, Kasparkova J, Bursova V, Hofr C, Vojtiskova M, Chen H, Sadler PJ, Brabec V. Chem Biol, 2005, 12: 121-129

Morris RE, Aird RE, del Socorro Murdoch P, Chen H, Cummings J, Hughes ND, Parsons S, Parkin A, Boyd G, Jodrell DI, Sadler PJ. J Med

Wu K, Liu S, Luo Q, Hu W, Li X, Wang F, Zheng R, Cui J, Sadler PJ, Xiang J, Shi Q, Xiong S. Inorg Chem, 2013, 52: 11332-11342 

7: 2864-2871

Payet D, Gaucheron F, Sip M, Leng M. Nucleic Acids Res, 1993, 21: 5846-5851

Dalbiès R, Boudvilliain M, Leng M. Nucleic Acids Res, 1995, 23: 949-953

Malina J, Kasparkova J, Farrell NP, Brabec V. Nucleic Acids Res, 2011, 39: 720-728

Liu S, Wu K, Zheng W, Zhao Y, Luo Q, Xiong S, Wang F. Analyst, 2014, 139: 4491-4496

Mowaka S, Ziehe M, Mohamed D, Hochkirch U, Thomale J, Linscheid MW. J Mass Spectrom, 2012, 47: 1282-1293

Bertrand H, Bombard S, Monchaud D, Talbot E, Guédin A, Mergny JL, Grünert R, Bednarski PJ, Teulade-Fichou MP. Org Biomol Chem, 2009,

Rao L, Bierbach U. J Am Chem Soc, 2007, 129: 15764-15765

McLuckey SA, Habibi-Goudarzi S. J Am Chem Soc, 1993, 115: 12085-12095

Wu K, Hu W, Luo Q, Li X, Xiong S, Sadler PJ, Wang F. J Am Soc Mass Spectrom, 2013, 24: 410-420

Barry CG, Day CS, Bierbach U. J Am Chem Soc, 2005, 127: 1160-1169

Egger AE, Hartinger CG, Ben Hamidane H, Tsybin YO, Keppler BK, Dyson PJ. Inorg Chem, 2008, 47: 10626-10633

Stucki SR, Nyakas A, Schürch S. J Mass Spectrom, 2011, 46: 1288-1297

Elmroth SKC, Lippard SJ. J Am Chem Soc, 1994, 116: 3633-3634

Neidle S, Parkinson G. Nat Rev Drug Discov, 2002, 1: 383-393

Parkinson GN, Lee MPH, Neidle S. Nature, 2002, 417: 876-880

Groessl M, Tsybin YO, Hartinger CG, Keppler BK, Dyson PJ. J Biol Inorg Chem, 2010, 15: 677-688

Iannitti-Tito P, Weimann A, Wickham G, Sheil MM. Analyst, 2000, 125: 627-634

Hagemeister T, Linscheid M. J Mass Spectrom, 2002, 37: 731-747

Casini A, Reedijk J. Chem Sci, 2012, 3: 3135-3144

Han Y, Luo Q, Hao X, Li X, Wang F, Hu W, Wu K, Lü S, Sadler PJ. Dalton Trans, 2011, 40: 11519-11529

Reedijk J. Chem Rev, 1999, 99: 2499-2510

Wang F, Bella J, Parkinson JA, Sadler PJ. J Biol Inorg Chem, 2005, 10: 147-155

Wang F, Chen H, Parkinson JA, Murdoch PS, Sadler PJ. Inorg Chem, 2002, 41: 4509-4523

Wang F, Xu J, Habtemariam A, Bella J, Sadler PJ. J Am Chem Soc, 2005, 127: 17734-17743

Kelland L. Nat Rev Cancer, 2007, 7: 573-584

Hu W, Luo Q, Ma X, Wu K, Liu J, Chen Y, Xiong S, Wang J, Sadler PJ, Wang F. Chem Eur J, 2009, 15: 6586-6594

Hu W, Luo Q, Wu K, Li X, Wang F, Chen Y, Ma X, Wang J, Liu J, Xiong S, Sadler PJ. Chem Commun, 2011, 47: 6006-6008

Li H, Lin TY, Van Orden SL, Zhao Y, Barrow MP, Pizarro AM, Qi Y, Sadler PJ, O’Connor PB. Anal Chem, 2011, 83: 9507-9515

Sooriyaarachchi M, Narendran A, Gailer J. Metallomics, 2011, 3: 49-55

Montero EI, Benedetti BT, Mangrum JB, Oehlsen MJ, Qu Y, Farrell NP. Dalton Trans, 2007, 2007: 4938

Allardyce CS, Dyson PJ, Coffey J, Johnson N. Rapid Commun Mass Spectrom, 2002, 16: 933-935

Guo W, Zheng W, Luo Q, Li X, Zhao Y, Xiong S, Wang F. Inorg Chem, 2013, 52: 5328-5338

Wang F, Weidt S, Xu J, Mackay CL, Langridge-Smith PRR, Sadler PJ. J Am Soc Mass Spectrom, 2008, 19: 544-549

Stewart AJ, Blindauer CA, Berezenko S, Sleep D, Sadler PJ. Proc Natl Acad Sci USA, 2003, 100: 3701-3706

Sweeney JD, Ziegler P, Pruet C, Spaulding MB. Cancer, 1989, 63: 2093-2095

Sun H, Li H, Sadler PJ. Chem Rev, 1999, 99: 2817-2842

Pongratz M, Schluga P, Jakupec MA, Arion VB, Hartinger CG, Allmaier G, Keppler BK. J Anal Atom Spectrom, 2004, 19: 46-51

Chitambar CR. Curr Opin Oncol, 2004, 16: 547-552

Harris WR, Chen Y, Wein K. Inorg Chem, 1994, 33: 4991-4998

Sun H, Li H, Weir RA, Sadler PJ. Angew Chim Int Ed, 1998, 37: 1577-1579

Brigger I, Dubernet C, Couvreur P. Adv Drug Deliver Rev, 2002, 54: 631-651

Qian ZM. Pharmacol Rev, 2002, 54: 561-587

Khalaila I, Allardyce CS, Verma CS, Dyson PJ. ChemBioChem, 2005, 6: 1788-1795

Cox MC, Barnham KJ, Frenkiel TA, Hoeschele JD, Mason AB, He QY, Woodworth RC, Sadler PJ. J Biol Inorg Chem, 1999, 4: 621-631

Tisato F, Marzano C, Porchia M, Pellei M, Santini C. Med Res Rev, 2010, 30: 708

Siddik ZH. Oncogene, 2003, 22: 7265-7279

Hamza I, Prohaska J, Gitlin JD. Proc Natl Acad Sci USA, 2003, 100: 1215-1220

Arnesano F, Banci L, Bertini I, Felli IC, Losacco M, Natile G. J Am Chem Soc, 2011, 133: 18361-18369

Boal AK, Rosenzweig AC. J Am Chem Soc, 2009, 131: 14196-14197 
Xi Z, Guo W, Tian C, Wang F, Liu Y. Chem Commun, 2013, 49: 11197-11199

Xi Z, Guo W, Tian C, Wang F, Liu Y. Metallomics, 2014, 6: 491-497

Banci L, Bertini I, Ciofi-Baffoni S, Leontari I, Martinelli M, Palumaa P, Sillard R, Wang S. Proc Natl Acad Sci USA, 2007, 104: 15-20

Palumaa P. FEBS Lett, 2013, 587: 1902-1910

Zhao L, Cheng Q, Wang Z, Xi Z, Xu D, Liu Y. Chem Commun, 2014, 50: 2667-2669

Li L, Guo W, Wu K, Wu X, Zhao L, Zhao Y, Luo Q, Wang Y, Liu Y, Zhang Q, Wang F. J Inorg Biochem, 2016, 161: 99-106

Tsuchida S, Sato K. Crit Rev Biochem Mol Biol, 1992, 27: 337-384

Wilce MCJ, Parker MW. BBA-Protein Struct Mol Enzym, 1994, 1205: 1-18

Lin Y, Huang Y, Zheng W, Wang F, Habtemariam A, Luo Q, Li X, Wu K, Sadler PJ, Xiong S. J Inorg Biochem, 2013, 128: 77-84

Cristoni S, Bernardi LR. Expert Rev Proteom, 2004, 1: 469-483

Pesavento JJ, Kim YB, Taylor GK, Kelleher NL. J Am Chem Soc, 2004, 126: 3386-3387

Demirev PA, Feldman AB, Kowalski P, Lin JS. Anal Chem, 2005, 77: 7455-7461

Hartinger CG, Tsybin YO, Fuchser J, Dyson PJ. Inorg Chem, 2008, 47: 17-19

Hartinger CG, Casini A, Duhot C, Tsybin YO, Messori L, Dyson PJ. J Inorg Biochem, 2008, 102: 2136-2141

Li H, Zhao Y, Phillips HIA, Qi Y, Lin TY, Sadler PJ, O’Connor PB. Anal Chem, 2011, 83: 5369-5376

Li L, Guo W, Wu K, Zhao Y, Luo Q, Zhang Q, Liu J, Xiong S, Wang F. Rapid Commun Mass Spectrom, 2016, 30: 168-172

Moreno-Gordaliza E, Cañas B, Palacios MA, Gómez-Gómez MM. Anal Chem, 2009, 81: 3507-3516

Zhang G, Hu W, Du Z, Lv S, Zheng W, Luo Q, Li X, Wu K, Han Y, Wang F. Int J Mass Spectrom, 2011, 307: 79-84

Mandal R, Li XF. Rapid Commun Mass Spectrom, 2006, 20: 48-52

Razumienko E, Ornatsky O, Kinach R, Milyavsky M, Lechman E, Baranov V, Winnik MA, Tanner SD. J Immunol Methods, 2008, 336: 56-63

Baranov VI, Quinn Z, Bandura DR, Tanner SD. Anal Chem, 2002, 74: 1629-1636

Baranov VI, Quinn ZA, Bandura DR, Tanner SD. J Anal Atom Spectrom, 2002, 17: 1148-1152

Bouyssiere B, Baco F, Savary L, Lobiñski R. J Chromatogr A, 2002, 976: 431-439

Kannamkumarath SS, Wrobel K, Wrobel K, B'Hymer C, Caruso JA. J Chromatogr A, 2002, 975: 245-266

Esteban-Fernández D, Cañas B, Pizarro I, Palacios MA, Gómez-Gómez MM. J Anal Atom Spectrom, 2007, 22: 1113-1121

Christodoulou J, Kashani M, Keohane BM, Sadler PJ. J Anal Atom Spectrom, 1996, 11: 1031-1035

Bytzek AK, Boeck K, Hermann G, Hann S, Keppler BK, Hartinger CG, Koellensperger G. Metallomics, 2011, 3: 1049-1055

Heffeter P, Böck K, Atil B, Reza Hoda MA, Körner W, Bartel C, Jungwirth U, Keppler BK, Micksche M, Berger W, Koellensperger G. J Biol Inorg Chem, 2010, 15: 737-748

Szpunar J. Analyst, 2005, 130: 442-465

Holtkamp H, Grabmann G, Hartinger CG. Electrophoresis, 2016, 37: 959-972

Szpunar J, Makarov A, Pieper T, Keppler BK, Łobiński R. Anal Chim Acta, 1999, 387: 135-144

Timerbaev AR, Aleksenko SS, Polec-Pawlak K, Ruzik R, Semenova O, Hartinger CG, Oszwaldowski S, Galanski M, Jarosz M, Keppler BK. Electrophoresis, 2004, 25: 1988-1995

Hartinger CG, Zorbas-Seifried S, Jakupec MA, Kynast B, Zorbas H, Keppler BK. J Inorg Biochem, 2006, 100: 891-904

Połeć-Pawlak K, Abramski JK, Ferenc J, Foteeva LS, Timerbaev AR, Keppler BK, Jarosz M. J Chromatogr A, 2008, 1192: $323-326$

Groessl M, Terenghi M, Casini A, Elviri L, Lobinski R, Dyson PJ. J Anal Atom Spectrom, 2010, 25: 305-313

Mandal R, Kalke R, Li XF. Chem Res Toxicol, 2004, 17: 1391-1397

Mandal R, Jiang G, Li XF. Appl Organom Chem, 2003, 17: 675-681

Lin Y, Huang Y, Zheng W, Wu K, Luo Q, Zhao Y, Xiong S, Wang F. J Inorg Biochem, 2015, 146: 44-51

Zabet-Moghaddam M, Kawamura T, Yatagai E, Niwayama S. Bioorg Med Chem Lett, 2008, 18: 4891-4895

Gasser G, Ott I, Metzler-Nolte N. J Med Chem, 2011, 54: 3-25

Hartinger CG, Metzler-Nolte N, Dyson PJ. Organometallics, 2012, 31: 5677-5685

Wedlock LE, Berners-Price SJ. Aust J Chem, 2011, 64: 692-704

Lee RFS, Escrig S, Croisier M, Clerc-Rosset S, Knott GW, Meibom A, Davey CA, Johnsson K, Dyson PJ. Chem Commun, 2015, 51: 16486-16489

Legin AA, Schintlmeister A, Jakupec MA, Galanski M, Lichtscheidl I, Wagner M, Keppler BK. Chem Sci, 2014, 5: 3135-3143

Wedlock LE, Kilburn MR, Cliff JB, Filgueira L, Saunders M, Berners-Price SJ. Metallomics, 2011, 3: 917-925

Du J, Zhang E, Zhao Y, Zheng W, Zhang Y, Lin Y, Wang Z, Luo Q, Wu K, Wang F. Metallomics, 2015, 7: 1573-1583

Cobice DF, Goodwin RJA, Andren PE, Nilsson A, Mackay CL, Andrew R. Brit J Pharmacol, 2015, 172: 3266-3283

Lanni EJ, Rubakhin SS, Sweedler JV. J Proteom, 2012, 75: 5036-5051 


\title{
Investigations of molecular mechanism of action of metal-based anticancer complexes by mass spectrometry
}

\author{
Kui Wu, Qun Luo, Yao Zhao, Wei Zheng, Fuyi Wang* \\ Beijing National Laboratory for Molecular Sciences, National Centre for Mass Spectrometry in Beijing; CAS Key Laboratory of Analytical Chemistry \\ for Living Biosystems, Institute of Chemistry, Chinese Academy of Sciences, Beijing 100190, China \\ *Corresponding author (email: fuyi.wang@iccas.ac.cn)
}

\begin{abstract}
Soft ionization mass spectrometry, including electrospray ionization (ESI) and matrix-assistant laser desorption/ionization (MALDI) mass spectrometry, has emerged to be one of the most powerful tool for studying the interactions between metal-based anticancer complexes and biological targets such as proteins and DNA. While the application of mass spectrometry imaging for the researches in the mechanism of action of anticancer metallodrugs in vitro and in vivo is being ascendant. Based on the research progress of our group in exploring the mechanism of action of metal-based anticancer complexes, this article summarizes and reviews the applications of mass spectrometry in deciphering the antitumor mechanism of platinum- and ruthenium-based anticancer complexes, discusses the update advances in the investigation of interactions between metal-based anticancer complexes and proteins/DNA by mass spectrometry, and looks into the future application and tendency at this cutting-edge research field.
\end{abstract}

Keywords: mass spectrometry, anticancer metallodrug, platinum, ruthenium, molecular mechanism of action doi: $10.1360 / \mathrm{N} 032016-00146$ 